CASE REPORT

\title{
HIV infection associated with Strongyloides stercoralis colitis resulting in Streptococcus bovis bacteraemia and meningitis
}

\author{
T de Silva, M Raychaudhuri, M Poulton
}

Sex Transm Infect 2005;81:276-277. doi: 10.1136/sti.2004.012393

We report the case of an HIV infected patient with Streptococcus bovis bacteraemia and meningitis associated with gastrointestinal Strongyloides stercoralis infection. To our knowledge, this has been reported once previously and serves as a reminder to actively exclude asymptomatic $S$ stercoralis infection in HIV infected individuals presenting with bacteraemia.

A 23 year old black African woman, presented with a 4 day history of fever and rigors, and 24 hours of severe frontotemporal headache, neck stiffness, and photophobia. She gave a 6 month history of weight loss and constipation, but denied diarrhoea. She reported previous episodes of malaria and a possible diagnosis of pulmonary tuberculosis, for which only 3 months treatment was given in Africa.

On examination her temperature was $39.7^{\circ} \mathrm{C}$, pulse 126/ minute, and blood pressure 133/73. She was alert, with mild neck stiffness and photophobia, but no focal neurological signs.

Funduscopy was unremarkable and there were no peripheral stigmata or murmurs suggestive of infective endocarditis. Lesions consistent with Kaposi's sarcoma were present on her shins.

Investigations showed haemoglobin $9.1 \mathrm{~g} / \mathrm{dl}$, white cell count (WCC) $4.68 \times 10^{9} / 1$ (neutrophils $2.67 \times 10^{9} /$, lymphocytes $1.28 \times 10^{9} / \mathrm{l}$, eosinophils $\left.0.31 \times 10^{9} / \mathrm{l}\right)$, platelets $185 \times 10^{9} /$, $\mathrm{Na}+122$, other electrolytes and liver function tests normal, C reactive protein $8.6 \mathrm{mg} / \mathrm{l}$, and malarial parasites not seen. Chest $\mathrm{x}$ ray was normal and a computed tomogram head scan was unremarkable. A lumbar puncture yielded turbid fluid with an opening pressure of $15.5 \mathrm{cmH}_{2} \mathrm{O}$. Microscopy revealed: red cells $155 \times 10^{6} / \mathrm{l}$, WCC $1625 \times 10^{6} / \mathrm{l}$ (predominantly polymorphs), and Gram positive cocci. Cerebrospinal fluid (CSF) protein was $4035 \mathrm{mg} / \mathrm{l}$ and glucose $0.2 \mathrm{mmol} / \mathrm{l}$ (serum $5.9 \mathrm{mmol} / \mathrm{l}$ ). Auramine stain for acid fast bacilli was negative.

Ceftriaxone was commenced and both CSF and blood culture subsequently isolated a Streptococcus bovis sensitive to penicillin ( $\mathrm{MIC}=0.064 \mathrm{mg} / \mathrm{l}$ ). Therapy was changed to Benzyl penicillin ( $12 \mathrm{MU} /$ day) to complete a 2 week course during which she made progressive improvement. Transoesophageal echocardiography failed to reveal any vegetations.

She was subsequently found to be HIV positive with a CD4 count of $175 \times 10^{6} / 1(12 \%)$, and a viral load of 304000 copies/ $\mathrm{ml}$. She was commenced on antiretroviral therapy with zidovudine, lamuvidine, and nevirapine. A colonoscopy showed erythematous mucosa with multiple small ulcers. Blood cytomegalovirus DNA was negative. Two weeks later the patient developed abdominal pain and vomiting. The eosinophil count was now $1.27 \times 109 / 1$ (total WCC $3.56 \times 10^{9}$ / 1). Histology from the colon showed marked infestation with $S$ stercoralis and special stains for acid fast bacilli, fungi, and cytomegalovirus were all negative. She was treated with a 5 day course of ivermectin ( $12 \mathrm{mg} /$ day $)$. Her symptoms resolved and eosinophil count normalised. She remains well 4 months later, with an undetectable viral load $(<50$ copies $/ \mathrm{ml})$.

\section{DISCUSSION}

Streptococcus bovis is a part of the gastrointestinal tract flora in $10-16 \%$ of healthy people and is a well recognised cause of bacteraemia and endocarditis. ${ }^{12}$ The association between this organism and colonic neoplasms is also well documented and an estimated $40.3 \%$ of patients with $S$ bovis bacteraemia or endocarditis are reported to have underlying gastrointestinal tumours. ${ }^{3}$ Meningitis due to $S$ bovis is extremely rare and there are only 21 previously reported cases.

$S$ stercoralis is an intestinal nematode endemic in many developing countries. Infection is frequently asymptomatic for long periods of time. Symptoms may consist of mild gastrointestinal discomfort and chronic diarrhoea. In those from endemic areas with diarrhoea, the incidence of $S$ stercoralis in HIV infected patients is thought to be higher than in HIV negative individuals and is estimated to be around $5-6 \%{ }^{4}$ It is unclear whether a similar increase is present in asymptomatic cases. The occurrence of bacteraemia in $S$ stercoralis infection is well documented and may result simply from bowel wall ulceration acting as a portal of entry for enteric organisms. There is some evidence that intestinal bacteria are also carried by invasive $S$ stercoralis larvae on their outer surfaces. ${ }^{5}$ Commonly associated bacteria include Escherichia coli, Klebsiella spp, and Streptococcus faecalis, with only two previously reported cases of $S$ bovis bacteraemia. $^{67}$

Our case illustrates the importance of actively investigating the gastrointestinal tract in patients with $S$ bovis bacteraemia. Furthermore, in HIV infected individuals with a history of travel to endemic areas one should exclude potentially fatal parasitic infections such as $S$ stercoralis.

\section{Key messages}

- Individuals with enteric organisms in sterile sites should have appropriate gastrointestinal investigations; in such individuals with a risk factor for strongyloides this should be ruled out, in particular in HIV positive individuals; and individuals with strongyloides may not have diarrhoea 


\section{CONTRIBUTORS}

TdS, MR, and MP were involved in the care of this patient during admission; MP followed up the patient; TdS and MR carried out the literature review and wrote the initial manuscript; MP reviewed the initial manuscript before submission and revised the manuscript before resubmission

\section{Authors' affiliations}

T de Silva, M Raychaudhuri, M Poulton, Kings College Hospital, London, UK

Correspondence to: Dr Mary Poulton, Caldecot Centre, Kings College Hospital, London SE5 9RS, UK; mary.poulton@kingsch.nhs.uk

Accepted for publication 12 August 2004

\section{REFERENCES}

1 Roses DF, Richman H, Localio SA. Bacterial endocarditis associated with colorectal carcinoma. Ann Surg 1974;179:190-1.

2 Klein RS, Recco RA, Catalano MT, et al. Association of Streptococcus bovis with carcinoma of the colon. N Engl J Med 1979;297:800-2

3 Waisberg J, Matheus C, Pimenta J. Infectious endocarditis from Streptococcus bovis associated with colonic carcinoma: case report and literature review. Arq Gastroenterol 2002;39:3.

4 Feitosa G, Bandeira AC, Sampaio DP, et al. High prevalence of giardiasis and strongyloidiasis among HIV-infected patients in Bahia, Brazil. Braz J Infect Dis 2001;5:339-44.

5 Grove DI. Human strongyloidiasis. Adv Parasitol 1996;38:251-309.

6 Jain AK, Agarwal SK, El-Sadr W. Streptococcus bovis bacteraemia and meningitis associated with Strongyloides stercoralis colitis in a patient infected with human immunodeficiency virus. Clin Infect Dis 1994; 18:253-4.

7 Link K, Orenstein R. Bacterial complications of strongyloidiasis: Streptococcus bovis Meningitis. Southern Med J 1999;92:728-31. 